\title{
A flexible ecosystem services proto-typology based on public opinion
}

Stapleton, L.M. ${ }^{\mathrm{a}}{ }^{*}$ Hanna, P. ${ }^{\mathrm{b}}$ Ravenscroft, N. ${ }^{\mathrm{a}}$ and Church, A. ${ }^{\mathrm{a}}$

a. School of Environment and Technology, Faculty of Science and Engineering, University of Brighton, Brighton, BN2 4GJ, Brighton, U.K.

b. School of Applied Social Science, Faculty of Health and Social Science, University of Brighton, BN1 9PH, Brighton, U.K.

1. Present address: SPRU (Science \& Technology Policy Research), School of Business, Management \& Economics, University of Sussex, Brighton, BN1 9SL, U.K. 


\section{Abstract}

2 Interest in the conception and application of ecosystem services has increased significantly

3 in recent years. However, there remains some doubt about the universality and utility of the

4 terminology used to describe these services. Public preferences for ecosystem service

5 terminology were elicited using an online survey $(n=145)$ of adults in the UK and other

6 countries. A list of different ecosystem phenomena was provided and respondents

7 identified each as a benefit, function, good and/or service. Results were generally robust to

8 subjective differences in familiarity with the subject matter. In the overall sample, benefit

9 was the most preferred descriptor followed by function, service and good. However, by

10 using a combination of non-parametric statistical tests, 10 descriptor sets emerged from the

11 data to describe 22 different ecosystem phenomena. Three of these descriptor sets were

12 individual words (benefit, function and good), covering 9 of the 22 ecosystem phenomena.

13 The other 7 descriptor sets were multiple words (e.g. benefit-good and benefit-functionservice) covering the remaining 13 ecosystem phenomena. Scoring the 22 ecosystem phenomena in terms of 4 characteristics (intake, solid, survive and visible) yielded mixed results in terms of being able to distinguish between descriptor sets based on the presence or absence of these characteristics. 
1

2

3

4

5

6

7

8

9

10

11

12

\section{Introduction}

'Ecosystem services' is an umbrella term that has been developed to refer to a particular conceptualisation of ecosystem phenomena. This conceptualisation is largely functional, with ecosystems categorised according to their utility to humans. This resonates, to many, with the market-driven terminology used by economists, with some authors distinguishing between different types of service, including cultural, provisioning, regulating and supporting ecosystem services (e.g. Fisher, et al, 2009; Hein, et al, 2006; MA, 2003, 2005; Mace et al., 2011). Research into ecosystem services has risen exponentially since the 1980s (Fisher et al., 2009) and boasts landmark, highly cited, texts. To emphasise the significance of marketisation, a seminal text has sought to provide a value for the global stock of ecosystem services (Costanza et al., 1997). More recently, the Millennium Ecosystem Assessment (MA) has sought to understand the current state and future outlook of ecosystem services for different countries around the world (MA 2005).

Despite the increasing use and application of ecosystem services terminology within academic arenas (see, for example, Costanza, et al, 1997; de Groot, et al, 2002; MA, 2003, 2005; Hein, et al, 2006; Wallace, 2007; Maynard, et al, 2010; Mace, et al, 2011; Nahlik, et al, 2012) understandings of 'ecosystem services' remain problematic within lay discourse according to a study conducted for the UK Government's Department for Environment, Food and Rural Affairs (Define Research \& Insight, 2007, p. 40). They concluded that the term Ecosystem services was too "baffling for most due to the lack of awareness of the term ecosystems". The related term Nature's services resonated better with people. The need to consider alternative ways of describing the services provided by ecosystems is corroborated 
1 by studies which have elicited views from the American public (Metz and Weigel, 2010) and

2 conducted textual analyses of UK web sites (Wild and McCarthy, 2010; Wild et al, 2013).

3 While it is tempting to agree that the term 'ecosystem services' is inappropriate as a general

4 conception, Fish (2011, p. 676) offers the following warning: "[an ecosystem services

5 assessment] loses much of its analytical power if it does not work with its own, very

6 particular, vocabulary". At the same time increasing emphasis is being placed on public

7 knowledge(s), public participation and public understanding of science with Luck et al (2012)

8 explaining that a key rationale for ecosystem assessments is communication and education.

9 Therefore it is important to investigate and apply ecosystem services terminology based on conceptual frameworks which take into account a wider set of preferences beyond those of networked groups of experts. As Fish (2011, p. 675) notes, beyond researchers, decision makers and other people actively involved in ecosystem services research "there is a need to encompass a much greater diversity of ideas, expertise and creative inspiration" (Fish, 2011, p. 675). This paper seeks to address this challenge by eliciting - for the first time public opinion about the appropriate ecosystem service terminology to use with respect to specific ecosystem phenomena. Previous studies (Define Research \& Insight, 2007; Metz and Weigel, 2010) have only elicited public preferences for ecosystem services terminology in general terms. In so doing the paper seeks to engage with debates about the relationship between group and individual decision-making, as a contribution to wider discussions about the nature and construction of expert and lay knowledges. 


\section{2. Problematic foundations}

2 According to Gómez-Baggethun et al (2010, p. 1213) “in the late 1960s and 1970s a series of

3

4 societies ${ }^{1 \prime \prime}$; they go on to list examples of these contributions by American, British and

5 Dutch academics. Beyond functions, Vihervaara et al (2010) state that the idea of ecosystem

6 goods and services was first suggested by Eugene Odum (1959) an American ecologist, at

7 The University of Georgia. But, according to Costanza and Kubiszewski (2012) and Gómez-

8 Baggethun et al (2010), it is Walter Westman (1977) - another American ecologist, this time

9 at The University of California, Los Angeles - who appears to be the first person to use the term ecosystem services. Whether this remains true outside of the academic literature published in the English language is an open question. At the same time Westman's article also appears to be the first to use and apply all four of the descriptors which are the focus of this paper - benefit, function and good as well as service. Reading Westman's original article it is interesting to note that he conceptualises (a) benefits as phenomena which emanate from goods; (b) functions and services as synonyms (c) benefits as phenomena which also emanate from these functions / services: "The structure of an ecosystem includes the species contained therein [...] [t]his is the ecosystem's standing stock-nature's free "goods". From the structural aspects of ecosystems, society reaps two kinds of "benefits": (i) the direct harvest of marketable products [...] and the procurement of the genetic resources of valuable species [...] and (ii) the use and appreciation of ecosystems for recreation, esthetic [sic] enjoyment, and study. The "functions" of an ecosystem, on the other hand, are characterized by the ways in which the components of the system interact.

\footnotetext{
${ }^{1}$ The appropriation of the word function by economists and its subsequent recasting in utilitarian terms is lamented by Peterson et el (2010).
} 
1 They are the dynamics of ecosystems -nature's free "services". These "functions" impart to

2 society a variety of "benefits". They include the absorption and breakdown of pollutants,

3 the cycling of nutrients [...]" (Ibid, p. 9612). Another early example which applies the concept

4 of ecosystem services is provided by two more American ecologists - Ehrlich and Mooney

5 (1983) - who also refer to ecosystem benefits and functions although no mention of

6 ecosystem goods is made. Instead, what Westman considered as goods, Ehrlich and Mooney

7 consider to be controllers which they define as "the organisms that determine the structure

8 of the ecosystem" (Ibid, p. 248). Although definitions of benefits, functions and services are

9 not provided by Ehrlich and Mooney, examples of services are given which suggest they are being defined in the same way as Westman defines services and functions.

11 The development of the ecosystem services literature since these early examples continues to be dominated by Western authors (Costanza and Kubiszewski, 2012), a dominance not circumvented by this paper whose authors are all (white, male) British researchers. The literature is also characterised by sustained differences of opinion as to whether and how the benefits, functions, goods and services associated with ecosystems differ from each other (de Groot et al., 2010). For example, Nahlik et al (2012) discuss how some authors equate benefits with services whilst others regard benefits to be phenomena which emanate from services. The two most well known examples they discuss - Costanza et al (1997) and MA (2005) - both take the former approach, by equating services and benefits.

A review of the current approach to conceptualising ecosystem services suggests that what is commonly presented as consensus is, at best, only localised consensus within and not between different groups of 'experts'. To illustrate the prevailing diversity of opinions

\footnotetext{
${ }^{2}$ Emboldening added by the authors.
} 
1 between different groups of experts, Table 1 describes some alternative descriptors put

2 forward for what the United Kingdom's National Ecosystem Assessment (UK NEA, Mace et al

3 2011) regarded as final ecosystem goods and services. The conceptual framework

4 developed by the UK NEA lists 11 different authors from a variety of institutions. Some

5 alternative frameworks in Table 1 boast higher numbers of contributors (e.g. MA, 2003,

6 2005; Maynard et al., 2010) at least ostensibly, depending on the actual structures and

7 processes of involvement. However what unites all of these studies is the presentation of a

8 consensus view based on the decisions of a group, or in the case of Wallace (2007), the

9 views of just one individual 'expert'. The tendency for these studies to appear in academic

10 journals as opposed to outlets more accessible to a general audience can be expected to

11 change over time because more projects will begin to be reported online which use the

12 increasingly popular ecosystem services terminology (Frykman, 2012).

13 Table 1. Alternative descriptors for what Mace et al (2011) identify as ecosystem goods and 14 services

\begin{tabular}{|c|c|c|c|c|c|}
\hline \multirow{2}{*}{ Reference } & \multicolumn{4}{|c|}{ Descriptors used } & \multirow[t]{2}{*}{ Who decided which descriptors should be used? } \\
\hline & Benefit & Function & Good & Service & \\
\hline Costanza et al (1997) & $\checkmark$ & & $\checkmark$ & $\checkmark$ & $\begin{array}{l}8 \text { people at } 8 \text { different academic institutions; } 2 \text { at } \\
\text { private institutions; } 1 \text { at a hybrid academic- } \\
\text { governmental institution; } 1 \text { at a governmental } \\
\text { institution. }\end{array}$ \\
\hline de Groot et al (2002) & & $\checkmark$ & $\checkmark$ & $\checkmark$ & 3 people at 3 different academic institutions. \\
\hline Hein et al (2006) & & & $\checkmark$ & $\checkmark$ & 3 people at the same academic institution. \\
\hline MA (2005) & $\checkmark$ & & & $\checkmark$ & $\begin{array}{l}61 \text { people from a variety of institutions c.f. the } \\
\text { conceptual framework developed in MA (2003) } \\
\text { which is used in MA (2005) }\end{array}$ \\
\hline Maynard et al (2010) & $\checkmark$ & $\checkmark$ & & $\checkmark$ & $\begin{array}{l}\text { A large (but unspecified) number of people from a } \\
\text { variety of institutions took part in two working } \\
\text { groups "to develop lists and descriptions of } \\
\text { ecosystem functions and ecosystem services" }\end{array}$ \\
\hline Nahlik et al $(2012)^{*}$ & & $\checkmark$ & $\checkmark$ & & $\begin{array}{l}3 \text { people at the same governmental institution; } 1 \text { at } \\
\text { an academic institution. }\end{array}$ \\
\hline Wallace $(2007)^{\ddagger}$ & $\checkmark$ & & & $\checkmark$ & 1 person at a governmental institution. \\
\hline
\end{tabular}

15 Other descriptors used: * human use, process, security and structural component; $\neq$ asset and process 
1 The existence of these differences of opinion has stimulated a certain amount of research

2 into exactly these differences - in terms of their identification and causes. Going beyond

3 this, although it is conceivable that these differences of opinion could have implications for

4 policy and planning (Lamarque et al.,2011), any such implications are difficult to discern not

5 least because there is very little evidence available which illustrates the effect of ecosystem

6 services research on decision making (McKenzie et al., 2014). Such services are often only

7 recognised as important once it is too late, after their degradation (Daily et al., 2009). In

8 terms of the causes of these differences of opinion, at least some people in the research

9 community may regard ecosystem services as a boundary object ${ }^{3}$ (Schröter et al. in press;

Star 2010; Star and Griesemer 1989) within which manoeuvring between related

terminology is to be expected. Schröter et al (In Press, p.5) also suggest that maybe we should expect the prevailing differences of opinion about terminology and definitions because ecosystem services research is still in its "development phase". Mollinga (2010) expands on this, noting how this developmental phase has been going on since at least the 1990s. However, multiple protagonists could be spending time and energy competing to champion their approaches (Harrington et al., 2010) for parochial reasons, rather than aiming for a field-wide consensus position. One implication of this might be that the array of alternative terminology and definitions which exists is reflective of dysfunctional group based decision making leading to sub-optimal outcomes i.e. a number of conflicting definitions and typologies which few people are really happy with.

Developing and applying ecosystem services terminology based on the collective agreement of a range of experts appears to be a rational approach to an important issue. When

\footnotetext{
${ }^{3}$ Beyond boundary objects Mollinga (2010) distinguishes two other types of boundary phenomena: concepts and settings. Ecosystem services would be classed as a boundary concept, rather than an object, according to this approach.
} 
1

2

considering understandings of group dynamics this solution appears even more plausible.

Research into group dynamics and the behaviours of individuals within group settings has a long history in suggesting 'process gain' as an outcome in which group performance is more, or better than, would be expected on the basis of the member characteristics (e.g. Shaw, 1932). For example, a classic study in the USA looking at the effectiveness of students working in groups, compared to students working on their own, found that across a range of exercises groups achieved more than individuals did and students in the group conditions used higher level reasoning strategies in completing the tasks (Gabbert et al 1986). In addition, it appears that it is not only the cumulative effect of individual knowledge that results in people performing better in groups but also that simply being in the presence of others also enhances productivity. For example, analysing data collected from 2,000 bicycle race times, Triplett (1898) found that racers who were competing with other cyclists rode significantly faster than cyclists who were racing against the clock.

With such an empirical dominance of research suggesting the benefits of group decision making over individual decision making it is no surprise that such an approach dominates the processes for arriving at conceptualisations of ecosystem services and related terminology. However, this tradition is not without its critics particularly when considering the political elite and 'expert' groups. For example, Janis's (1972) groupthink hypothesis remains as dominant today as it ever has within the domain of social psychology. His work developed the notion that rather than a group of experts working together resulting in increased productivity and enhanced reasoning strategies, 'groupthink' results in capable and competent individuals making poor decisions. Janis draws on qualitative data from high profile political decisions to explore the ways in which group dynamics result in 
1 dysfunctional, irrational and problematic decisions, despite the 'expert' status of all

2 involved. In addition, critical scholars state that whilst the perspectives of 'experts' are

3 often seen as desirable in arriving at shared definitions, this only serves to privilege

4 particular forms of knowledge and marginalise the popular understandings of the lay

5 person' (Foucault, 1990/1976). Such an understanding has been well received in a range of

6 areas such as: health (Prior, 2003); food risks (Shaw, 1999); alternative medical practice

7 (McClean, 2003); and ecosystem risk (Lazo, et al, 2000).

8 So it is with ecosystem services, where particular forms of knowledge have contributed to 9 creating an opaque terminology that has found favour in policy arenas while seemingly 10 marginalising popular understandings of people-nature relations. In recognising Fish's 11 (2011) call to maintain a single vocabulary, this paper seeks to examine how far the established terminology can be reconceptualised in lay discourse to provide more universal access to debates surrounding ecosystem management.

\section{Methodology}

An online survey was developed and distributed by the four authors of this paper who carry out multidisciplinary environmental research (including ecosystem services research) based on their training in (broadly) economics, geography, ecology and psychology. This kind of multidisciplinary experience is important for successful research in the area of ecosystem services (Vihervaara et al, 2010). The principal survey question listed, alphabetically, the 24 'final ecosystem goods and services' (hereafter ecosystem phenomena) articulated in the UK NEA (Mace et al., 2011, p. 18). We decided not to incorporate extra terminology from other typologies relating to either additional ecosystem phenomena or existing ecosystem phenomena described in different words. This was justified in terms of keeping the list at a 
manageable size from the perspective of respondents, with a view to maximising survey response rate. For each ecosystem phenomenon, respondents were instructed to select whether they thought it was a benefit, function, good or service. In addressing people's possible unfamiliarity with the word 'ecosystem' (Design Research \& Insight 2007; Wild and McCarthy, 2010; Wild et al, 2013), the survey preamble asked people to think in terms of what is provided by the 'environment' or 'nature'.

A key feature of the survey instrument was that it did not provide definitions for the four descriptors - benefit, function, good and service. Crucially we wanted people to apply their own understandings to these terms not least because there are multiple possible definitions and interpretations that could be applied. Multiple responses per phenomenon were explicitly permitted so that, for example, something could be recorded as being both a good and a service (or indeed a benefit, function, good and service) if desired by the respondent. The option to select 'don't know' and 'other' in each case was also provided and respondents were asked to provide further details if and when these options were selected.

The survey was piloted $(n=12)$ in March 2013. Minor modifications and exemplifications were made to some of the ecosystem phenomena compared to how they are written in Mace et al. (2011), in order to improve their accessibility to a wider audience (as per Table 3). These changes were made based on the views of the authors in combination with the views of respondents to the pilot survey. For example, the ecosystem phenomenon 'equable climate' in Mace et al (2011) is modified to 'stable climate' in the survey, whilst the ecosystem phenomenon 'environmental settings' is exemplified as 'environmental settings e.g. beaches, gardens and parks'. In all cases where changes were made, care was taken to ensure that the new representations were synonymous with those in Mace et al (2011), so 
1

2

3

4

5

6

7

8

9

that the results of the survey are not a design artefact. Other questions in the survey asked respondents to record their: gender; age; nationality; level of education; their (subjectively determined) familiarity with the idea that ecosystems provide things that could be labelled as benefits, functions, goods and services (a 5-point Likert item ranging from Very familiar to Very unfamiliar); any other feedback. The final survey was completed ( $n=145)$ in April 2013 relying on availability and snowball sampling via e-mail and social media for responses.

\section{Results and Discussion}

The majority ( 86 or $59.3 \%$ ) of the 145 respondents were female, from the UK (118 or $81.4 \%$ ) and educated to postgraduate level (81 or 55.9\%). Ages ranged from 20-67 (mean $=43.85$ ). One-third (33.8\%) of the respondents identified themselves as being either 'quite familiar' or 'very familiar' with the idea that ecosystems provide things that could be labelled as benefits, functions, good and services (Figure 1). This provides an upper bound estimate ${ }^{4}$ of the proportion of our sample, and possibly the population at large, who interact with or use this terminology in some way. However, whether this is active interaction / use or something more passive such as reading and understanding material on this topic which appears in the popular media, websites or more specialist literature is not possible to discern from our data. Interestingly, familiarity does not differ significantly by gender ${ }^{5}$ (chi$s q=6.296 ; P=0.178>0.05)$ and showed no significant relationship when considered in terms of education (Spearman's rho $=-0.43 ; \mathrm{P}=0.615>0.05$ ) or age (Spearman's rho $=-0.76$; $P=0.365>0.05)$.

\footnotetext{
${ }^{4}$ It is an upper-bound because it is reasonable to assume that people less familiar with the concepts investigated in the survey would be less likely to complete it.

${ }^{5}$ The number of non-UK respondents was too small to test for significant differences between nationality and familiarity.
} 
1 Figure 1. Familiarity of survey respondents with the idea that ecosystems provide things

2 that could be labelled as benefits, functions, good and services

3

4 Overall, benefit was the descriptor most frequently used by respondents, followed by

function, service and then good (Figure 2). 'Other' and 'don't know' were selected

infrequently. The fact that the 'other' option was used so infrequently overall suggests that

the descriptors provided do not, generally, need to be accompanied or replaced by nonanthropocentric metaphors as suggested by Luck et al (2012). However, specific phenomena may not be very well described by either benefit, function, good or service, even if the majority are. When asked to describe their use of 'other', 3 survey respondents specifically complained about the anthropocentric nature of the terminology. In the words of one:

"[t]he 'ecosystem services' approach is entirely anthropocentric. It is all about ecosystems doing favours to people, which is a weird way of seeing the world. Actually, people are part of Nature. The ecosystems were here before humans evolved and will probably be here after we are extinct. Not that I believe exclusively in ecocentrism".

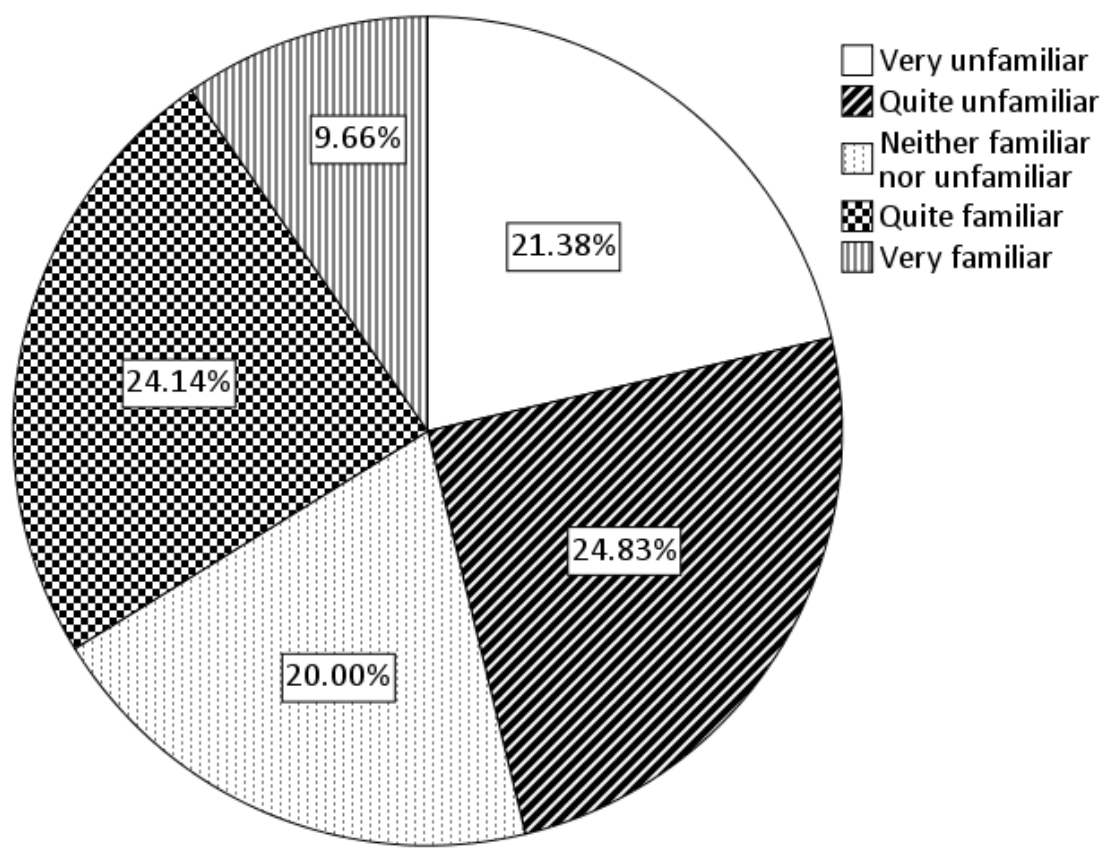


1 Three people offered alternative single descriptors: cost; love; process. One further person

2 offered an array: bad; dysfunction; harm; liability. Finally, despite its limited use by

3 respondents, we recognise that preferences for the 'other' option could be biased

4 downwards because providing particular (benefit, function, good and service) descriptors

5 implicitly suggests that they are sufficient options.

6 Similarly, the limited use of 'don't know' overall goes some way to suggest that this subject

7 matter is not too complex for public participation and engagement. We recognise that our

8 respondents are not a random sample of adults; $55.9 \%$ are listed as being educated to

9 postgraduate level. However, as noted above, there was no significant relationship between

10 familiarity with this subject and level of education in our sample. Thus, although biased

11 towards people who have spent a relatively long time in formal education, the sample is not

12 necessarily biased towards people who are more familiar with this subject compared to the

13 population.

Figure 2. Aggregated unweighted preferences for descriptors used to label 24 ecosystem phenomena

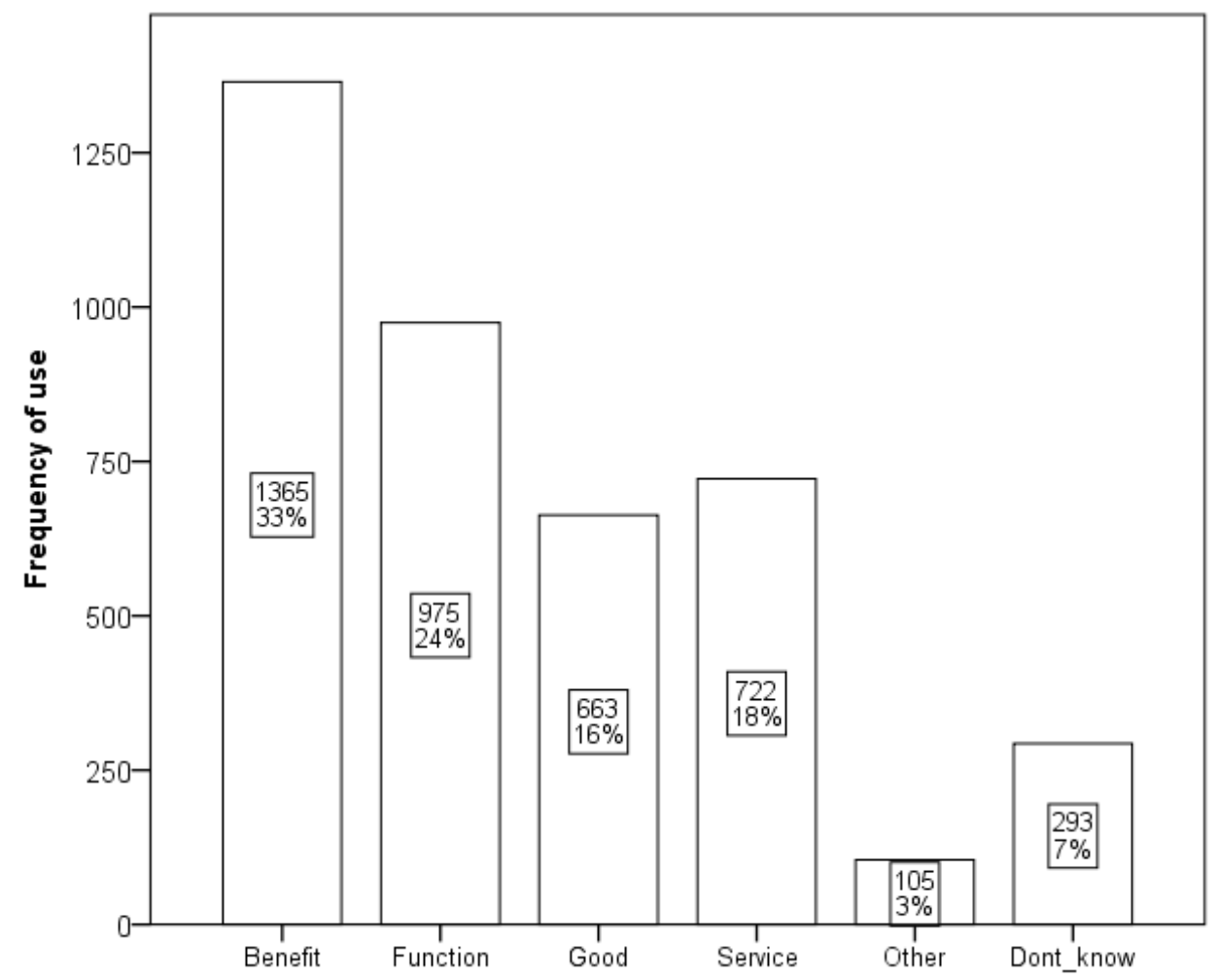


1 Weighted analysis which discriminates in favour of those with more objective domain

2 knowledge is variously used (e.g. Cooke, 1991; Aspinall, 2010) by including seed questions.

3 Here, weights were calculated based on subjective familiarity with the idea that ecosystems

4 provide things that could be labelled as benefits, functions, goods and services. Specifically,

5 dividing familiarity scores (which range from $1=$ Very unfamiliar to $5=$ Very familiar) by 2 .

6 Thus, where 1 indicated a respondent who selected a particular descriptor in the

7 unweighted data, using weights creates an array of alternative values depending on

8 familiarity, ranging from (1/2=) 0.5 where very unfamiliar respondents selected a particular

9 descriptor to $(5 / 2=) 2.5$ in the case of those very familiar with the subject. Aggregated weighted preferences (Figure 3 ) are very similar to the unweighted alternatives, despite the fact that large weights were used which discriminate heavily in favour of more familiar respondents. The nearest thing to a notable difference between the two sets of aggregated preferences is in terms of the 'don't know' option which was used less frequently in the weighted (4\%) compared to the unweighted (7\%) data. This goes some way to suggest that the descriptors selected by respondents are robust to differences in familiarity with the subject. However, aggregated analyses such as this could hide differences at the level of specific phenomena if they exist; this is examined next. 
1 Figure 3. Aggregated weighted preferences for descriptors used to label 24 ecosystem 2 phenomena

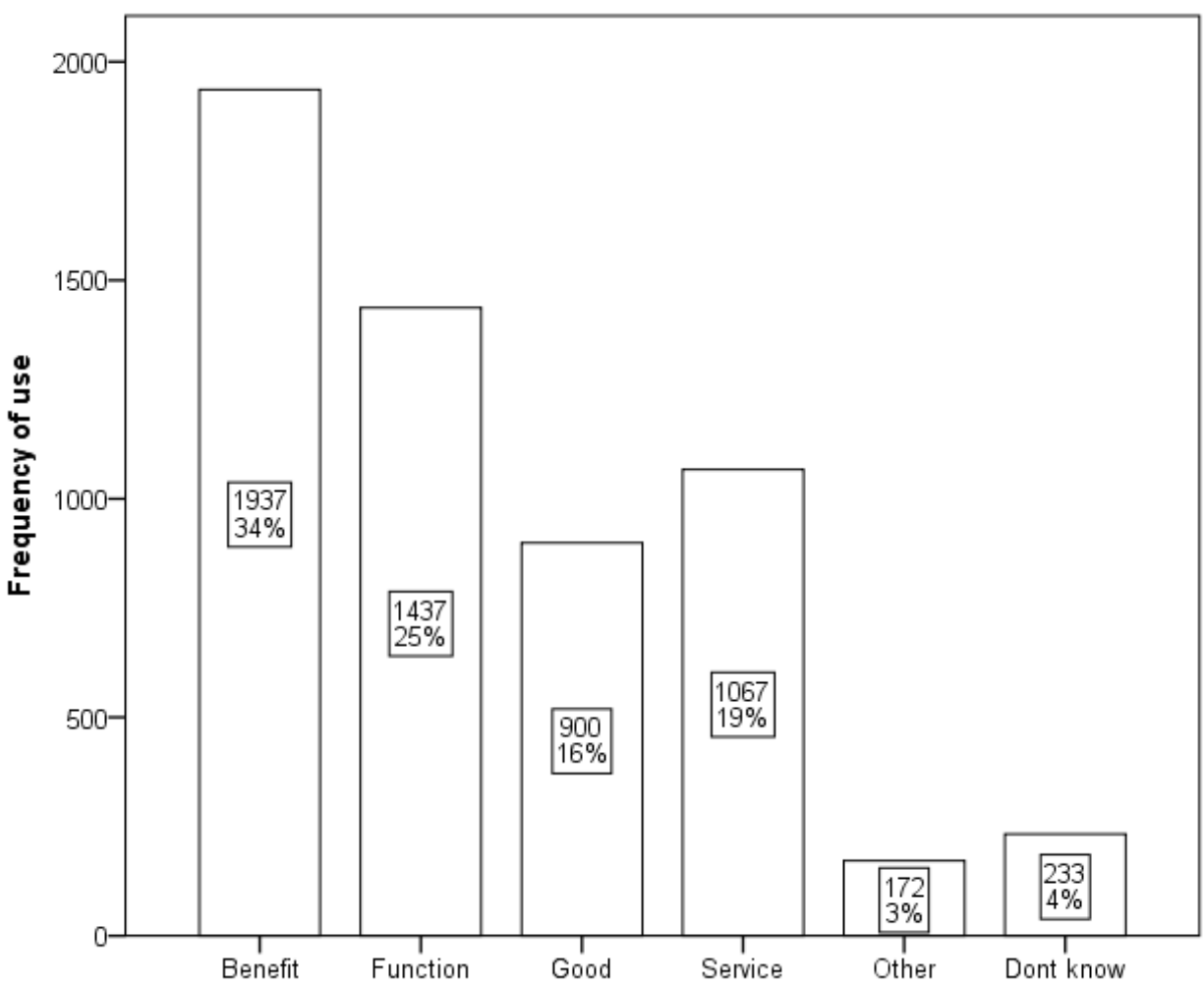

4

5 In the unweighted data, an average of $14.5 \%$ of respondents selected multiple descriptors

6 to describe ecosystem phenomena ranging from 6.2\% (tied between Spiritual and religious

7 experiences and Aesthetic experiences and inspiration) to 20.0\% (Detoxification and

8 purification in air, soils and water) of respondents. A similar story emerges from the

9 weighted data where an average of $14.8 \%$ of respondents selected multiple descriptors

10 ranging from $6.0 \%$ (Aesthetic experiences and inspiration) ${ }^{6}$ to $19.5 \%$ (Detoxification and

11 purification in air, soils and water) of respondents. This suggests that, intra-subjectively, the

12 concepts represented by the four descriptors (benefit, function, good and service) are

13 somewhat (but not highly) related.

\footnotetext{
${ }^{6}$ Spiritual and religious experiences was the phenomenon next least associated with multiple descriptors in the weighted data (7.5\% of respondents).
} 
1 The ecosystem phenomena which were most and least associated with different descriptors

2 also showed little variation between unweighted and weighted data (Table 2). Only once

3 does a difference emerge: 'service' tends to be used most in the context of Flood control

4 and Disease and pest control in unweighted and weighted data respectively. 'Other' was

5 (relative to its use overall) frequently selected for the phenomenon Spiritual and religious

6 experiences: 13\% of responses (weighted and unweighted data).

7 Table 2. The ecosystem phenomena most and least associated with different descriptors

\begin{tabular}{|c|c|c|c|c|}
\hline Descriptor & $\begin{array}{l}\text { Weighted / } \\
\text { Unweighted }\end{array}$ & $\begin{array}{l}\text { Most / } \\
\text { Least }\end{array}$ & Ecosystem Phenomenon & $\begin{array}{c}\% \text { of } \\
\text { Responses }\end{array}$ \\
\hline \multirow{4}{*}{ Benefit } & \multirow[t]{2}{*}{ X / 2 Weights } & Most & Aesthetic experiences and inspiration & $69 \%$ \\
\hline & & Least & Climate regulation & $21 \%$ \\
\hline & \multirow[t]{2}{*}{ Unweighted } & Most & Aesthetic experiences and inspiration & $64 \%$ \\
\hline & & Least & Climate regulation & $22 \%$ \\
\hline \multirow{4}{*}{ Function } & \multirow[t]{2}{*}{ X / 2 Weights } & Most & Climate regulation & $60 \%$ \\
\hline & & Least & Spiritual and religious experiences & $5 \%$ \\
\hline & \multirow[t]{2}{*}{ Unweighted } & Most & Climate regulation & $57 \%$ \\
\hline & & Least & Spiritual and religious experiences & $4 \%$ \\
\hline \multirow{4}{*}{ Good } & \multirow[t]{2}{*}{ X / 2 Weights } & Most & Crops, livestock and fish & $43 \%$ \\
\hline & & Least & Climate regulation & $2 \%$ \\
\hline & \multirow[t]{2}{*}{ Unweighted } & Most & Crops, livestock and fish & $42 \%$ \\
\hline & & Least & Climate regulation & $2 \%$ \\
\hline \multirow{4}{*}{ Service } & \multirow[t]{2}{*}{ X / 2 Weights } & Most & Disease and pest control & $36 \%$ \\
\hline & & Least & Wild species diversity & $5 \%$ \\
\hline & \multirow[t]{2}{*}{ Unweighted } & Most & Flood control & $33 \%$ \\
\hline & & Least & Wild species diversity & $4 \%$ \\
\hline \multirow{4}{*}{ Other } & \multirow[t]{2}{*}{ X / 2 Weights } & Most & Spiritual and religious experiences & $13 \%$ \\
\hline & & Least & Water supply & $1 \%$ \\
\hline & \multirow[t]{2}{*}{ Unweighted } & Most & Spiritual and religious experiences & $13 \%$ \\
\hline & & Least & Water supply & $1 \%$ \\
\hline \multirow{4}{*}{$\begin{array}{l}\text { Don't } \\
\text { know }\end{array}$} & \multirow[t]{2}{*}{ X / 2 Weights } & Most & Spiritual and religious experiences & $14 \%$ \\
\hline & & Least & Water supply & $1 \%$ \\
\hline & \multirow[t]{2}{*}{ Unweighted } & Most & Spiritual and religious experiences & $17 \%$ \\
\hline & & Least & Water supply & $3 \%$ \\
\hline
\end{tabular}

8

9 In terms of specific phenomena, using unweighted data, benefit is the most popular 10 descriptor in 10 cases followed by function in 6 cases. Both good and service are the most 
1 popular choice in 4 cases (Table 3 ). Given that only these latter two terms were used in

2 Mace et al (2011), denoting 13 (good) and 11 (service) phenomena, their relative lack of

3 popularity according to the results of the survey suggests that wider vocabulary is required

4 in order to describe these phenomena adequately.

5 Table 3. Disaggregated unweighted and weighted preferences for different descriptors used 6 to label 24 ecosystem phenomena

\begin{tabular}{|c|c|c|c|c|c|}
\hline & 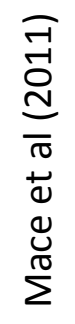 & 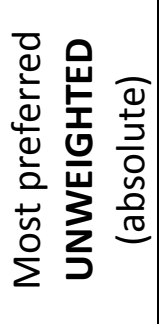 & 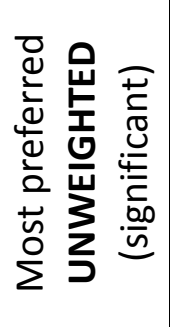 & 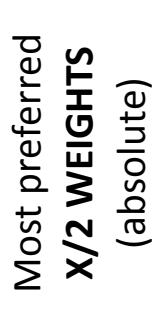 & 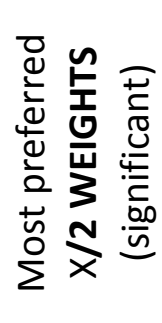 \\
\hline Aesthetic experiences and inspiration & G & B & B & B & B \\
\hline Climate regulation & $\mathbf{S}$ & $\mathbf{F}$ & $\mathbf{F}$ & $\mathbf{F}$ & $\mathbf{F}$ \\
\hline Crops, livestock and fish & $\mathbf{S}$ & G & G & G & G \\
\hline Detoxification and purification in air, soils and water & $\mathbf{S}$ & $\mathbf{F}$ & $\mathbf{F}$ & $\mathbf{F}$ & F S \\
\hline Disease and pest control & G & $\mathbf{S}$ & B F S & $\mathbf{S}$ & B F S \\
\hline Disease and pest regulation & $\mathbf{S}$ & $\mathbf{F}$ & B F S & $\mathbf{F}$ & B F S \\
\hline Drinking water & G & G & B G & G & B G \\
\hline Energy & G & G & B G S & G & B G S \\
\hline Environmental settings e.g. beaches, gardens and parks & $\mathbf{S}$ & B & B & B & B \\
\hline Soil erosion control & G & $\mathbf{F}$ & B F S & $\mathbf{F}$ & B F S \\
\hline Fibre to help digest food & G & B & B F G & B & B F G \\
\hline Flood control & G & $\mathbf{S}$ & B F S & $\mathbf{S}$ & B F S \\
\hline Food & G & G & $\mathbf{G}$ & $\mathbf{G}$ & $\mathbf{G}$ \\
\hline Natural hazard regulation e.g. flood regulation & $\mathbf{S}$ & $\mathbf{F}$ & B F S & $\mathbf{F}$ & B F S \\
\hline Natural medicine & G & B & B & B & B \\
\hline Noise regulation & $\mathbf{S}$ & $\mathbf{S}$ & B F S & B & B F S \\
\hline Pollination & $\mathbf{S}$ & $\mathbf{F}$ & $\mathbf{F}$ & $\mathbf{F}$ & $\mathbf{F}$ \\
\hline Pollution and noise control & G & B & B S & B & B S \\
\hline Recreation and tourism & $\mathbf{G}$ & B & B & B & B \\
\hline Spiritual and religious experiences & $\mathbf{G}$ & B & B & B & B \\
\hline Stable climate & $\mathbf{G}$ & B & B F & $\mathbf{F}$ & B F \\
\hline Trees, standing vegetation and peat & $\mathbf{S}$ & B & B G & B & B G \\
\hline Water supply & $\mathbf{S}$ & B & B F G S & B & B F G S \\
\hline Wild species diversity & $\mathbf{S}$ & B & B & B & B F \\
\hline
\end{tabular}


1 A more nuanced picture of the unweighted data emerges if we consider which descriptors

2

are the most popular in statistically significant terms. Using a combination of McNemar's

tests and Cochran's $Q$ tests applicable to dependent dichotomous data ${ }^{7}$, single descriptors are the most preferred option for only 11 out of the 24 different ecosystem phenomena.

This suggests that, inter-subjectively, the concepts represented by the four descriptors (benefit, function, good and service) are highly related. Benefit appears in all 13 cases where multiple descriptors are significantly popular. Water supply shows the greatest discordance of opinion with no significant differences in preference for calling this a benefit, function, good or service. In a further 8 cases, 3 descriptors per phenomenon are recorded.

Using data weighted dependent on subjective familiarity, there are only a few changes in terms of the most popular descriptors. In absolute terms, benefit is still the most popular descriptor in 10 cases: noise regulation, considered as a service in the unweighted data, is a benefit; stable climate, previously considered as a benefit, is a function. Similarly, there are only a few changes when considering popularity in statistically significant terms compared to unweighted data. Using a combination of Wilcoxon's signed rank tests and Friedman's tests applicable to dependent ordinal data $^{8}$, differences only emerge in terms of the phenomena Detoxification and purification in airs soils and water and Wild species diversity. The former changes from being considered as a function to being considered to be a

\footnotetext{
7 Dependent sample tests for dichotomous data are used because respondents could select multiple descriptors per phenomenon. McNemar's test is used to confirm or refute significant differences between the most preferred descriptor and the second most preferred. Where significant differences are not confirmed (i.e. there are at least 2 preferred descriptors per ecosystem phenomenon), Cochran's $Q$ is used to confirm or refute significant differences between the 3 most preferred descriptors and so on.

${ }^{8}$ Dependent sample tests for ordinal data are used because respondents could select multiple descriptors per phenomenon; these weighted data effectively ordinalise selections beyond nominal presence / absence. Wilcoxon's signed rank test is used to confirm or refute significant differences between the most preferred descriptor and the second most preferred. Where significant differences are not confirmed (i.e. there are at least 2 preferred descriptors per ecosystem phenomenon), Friedman's test is used to confirm or refute significant differences between the 3 most preferred descriptors and so on.
} 
1 function and a service. The latter shifts from being considered a benefit to being considered

2 a benefit and a function.

3 Weighted results could potentially differ from unweighted results in $48(24 \times 2)$ basic ways:

4 in terms of the most preferred descriptors for each of the 24 ecosystem phenomena as

5 presented in 2 (absolute and significant) forms. In fact, the results only differ in 4 ways (8\%),

6 as just described. The marked lack of difference in results again suggests that the

7 descriptors elicited in the survey are robust to differences in familiarity with the subject.

8 This provides further support for the idea that the questions posed in the survey are not

9 beyond public comprehension.

10 A key feature of the survey was that it did not provide definitions for the four descriptors;

11 rather, we wanted people to apply their own understandings to these terms. Focussing on the 22 ecosystem phenomena where the statistically significant descriptors across the weighted and unweighted data were the same (i.e. excluding Detoxification and purification in airs soils and water and Wild species diversity) four characteristics of these phenomena can be used to try and bound the 10 descriptor sets that were revealed in the data (Table 4). These characteristics are: INTAKE (Is this phenomenon something that is swallowed or absorbed by humans?); SOLID (Is this phenomenon firm in terms of shape?); SURVIVE (IS this phenomenon important to human survival?); and VISIBLE (Is it possible to see this phenomenon?). These four characteristics were devised by the authors rather than emanating from the literature. They were chosen because they are fundamental objective characteristics of different phenomena as opposed to semi-objective characteristics like welfare enhancing or subjective characteristics like beautiful, esoteric and stimulating. 
1 Table 4. Characteristics of ecosystem phenomena grouped according to statistically

2 significant descriptor sets which are constant across unweighted and weighted data

\begin{tabular}{|c|c|c|c|c|c|c|}
\hline 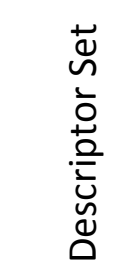 & Ecosystem Phenomena & 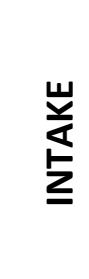 & 음 & 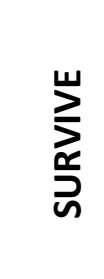 & $\begin{array}{l}\stackrel{\uplus}{\Xi} \\
\frac{\mathscr{n}}{>}\end{array}$ & 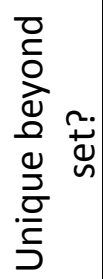 \\
\hline \multirow[t]{5}{*}{ B } & (1) Aesthetic experiences and inspiration & 1 & 1 & 2 & 1 & $\mathbf{Y}$ \\
\hline & (2) Environmental settings e.g. beaches gardens and & 1 & 3 & 2 & 3 & $\mathbf{Y}$ \\
\hline & (3) Natural medicine & 3 & 2 & 3 & 3 & $\mathbf{Y}$ \\
\hline & (4) Recreation and tourism & 1 & 1 & 2 & 2 & $\mathbf{Y}$ \\
\hline & (5) Spiritual and religious experiences & 1 & 1 & 2 & 1 & $\mathbf{Y}$ \\
\hline \multirow[t]{2}{*}{$\mathbf{F}$} & (1) Pollination & 1 & 1 & 3 & 2 & $\mathbf{N}$ \\
\hline & (2) Climate regulation & 1 & 1 & 3 & 1 & $\mathbf{N}$ \\
\hline \multirow[t]{2}{*}{ G } & (1) Crops, livestock and fish & 2 & 3 & 3 & 3 & $\mathbf{Y}$ \\
\hline & (2) Food & 3 & 3 & 3 & 3 & $\mathbf{Y}$ \\
\hline B F & (1) Stable climate & 1 & 1 & 3 & 2 & $\mathbf{N}$ \\
\hline \multirow[t]{2}{*}{ B G } & (1) Drinking water & 3 & 1 & 3 & 3 & $\mathbf{Y}$ \\
\hline & (2) Trees, standing vegetation and peat & 1 & 3 & 3 & 3 & $\mathbf{Y}$ \\
\hline B S & (1) Pollution and noise control & 1 & 1 & 3 & 1 & $\mathbf{N}$ \\
\hline B F G & (1) Fibre to help digest food & 3 & 3 & 3 & 2 & $\mathbf{Y}$ \\
\hline \multirow[t]{6}{*}{ B F S } & (1) Disease and pest control & 1 & 1 & 3 & 1 & $\mathbf{N}$ \\
\hline & (2) Disease and pest regulation & 1 & 1 & 3 & 1 & $\mathbf{N}$ \\
\hline & (3) Soil erosion control & 1 & 1 & 3 & 1 & $\mathbf{N}$ \\
\hline & (4) Flood control & 1 & 1 & 3 & 1 & $\mathbf{N}$ \\
\hline & (5) Natural hazard regulation e.g. flood regulation & 1 & 1 & 3 & 1 & $\mathbf{N}$ \\
\hline & (6) Noise regulation & 1 & 1 & 3 & 1 & $\mathbf{N}$ \\
\hline B G S & (1) Energy & 2 & 2 & 3 & 2 & $Y$ \\
\hline B F G S & (1) Water supply & 1 & 1 & 3 & 2 & $\mathbf{N}$ \\
\hline
\end{tabular}

3

4 Consideration in terms of these four characteristics discriminates effectively in 11 out of 22

5 cases. In other words, $50 \%$ of the time ecosystem phenomena are assigned to a particular

6 descriptor set they do not score the same as phenomena assigned to other descriptor sets

7 (see final column of Table 4. Where discrimination fails to occur this does not tend to be 
between ecosystem phenomena which are assigned to descriptor sets which are mutually exclusive. The scores for Pollination are the same as Stable climate and Water supply: a benefit, a benefit / function and a benefit / function / good / service respectively. All three thus have benefit in common, and two share function. All six phenomena in the benefit / function / service set share the same scores but this is not unique because these scores are also shared by Climate regulation (function) and Pollution and noise control (benefit and service). No descriptor unites all phenomena in this case but only the latter two are mutually exclusive.

Finally, it is useful to consider the relationship between the number of descriptors in a set (which are derived from the intersubjective preferences of survey respondents) versus the intrasubjective propensities of survey respondents to select multiple descriptors for different phenomena. Perhaps surprisingly, no such relationship exists according to both the unweighted (Pearson's $r=0.187 ; P=0.382>0.05$ ) or the weighted (Pearson's $r=0.231$; $P=0.278>0.05$ ) data. Put differently, as the number of descriptors in a set used to describe different ecosystem phenomena increases from 1 to 4 there is no significant concomitant increase (or decrease) in the likelihood that individual respondents would have selected multiple descriptors with respect to different ecosystem phenomena.

\section{Conclusions and suggestions for future research}

The debate about appropriate terminology to use in the context of ecosystem services research is not something that should be confined to 'experts' in the field. When asked which descriptors should be applied to 24 different ecosystem phenomena, 'don't know' was infrequently selected by respondents. A principal conclusion from this research is that multiple descriptors should be considered for, at least some, ecosystem phenomena. This 
1 would create typologies which resonate better with a broader spread of public opinion. This

2 could also resonate better with a wider set of experts in the field given that existing expert-

3 led typologies cannot agree on which single descriptors are best suited to denote particular

4 phenomena. The flexible proto-typology which emerges from statistical analysis of the

5 survey data is robust to differences in subjective familiarity with the subject matter. It is

6 flexible for two reasons. It does not constrain specific ecosystem phenomena to be denoted

7 by just a single descriptor. Neither does it impose definitions for benefit, function, good or

8 service: survey respondents were asked to apply their own explicit or tacit definitions. Our

9 attempt to reveal which explicit or tacit definitions were applied by scoring the emergent descriptor sets in terms of four characteristics suggests that more work is required in terms of exploring additional criteria which may bound these descriptor sets. This needs to be done in the context of a further survey which replicates certain features of the survey outlined in this research. That survey should aim to elicit terminology preferences from a larger, randomly selected, sample. Our subjective familiarity question could also reasonably be complemented by a seed question designed to elicit objective familiarity with the subject matter (Cooke, 1991; Aspinall, 2010). If further work still suggests that criteria are unable to bound descriptor sets, then the descriptors (or even some of the ecosystem phenomena) are conceptualised in significantly different ways by the majority of people. These differences in conceptualisation could represent valid rather than pseudo-opinions (Chaigneau et al., 2012) assuming that survey responses are still insensitive to subjective (or objective) familiarity with the subject matter. Alternatively, they may be fallible and subject to change in the future, just as expert opinions can change depending on a variety of factors 23 (Friedman and Thellefsen, 2011) such as variations in lay meanings or connotations of different words. 
1

2

\section{Acknowledgments}

We are grateful to the feedback and suggestions provided by two anonymous reviewers which helped us to materially improve the manuscript.

\section{References}

Aspinall, W. 2010. A route to more tractable expert advice. Nature 463, 294-295.

Chaigneau, S. E., Canessa, E., Gaete, J. 2012. Conceptual agreement theory. New Ideas in Psychology 30, 179-189.

Cooke, R.M. 1999. Experts in Uncertainty: Opinion and Subjective Probability in Science. Oxford University Press, Oxford United Kingdom.

Costanza, R., d'Arge, R.C., De Groot, R., Farber, S., Grasso, M., Hannon, B., Limburg, K., Naeem, S., O'Neill, R.V., Paruelo, J., Raskin, R.G., Sutton, P., van den Belt, M. 1997. The value of the world's ecosystem services and natural capital. Nature 387, 253-260.

Costanza, R., Kubiszewski, I. 2012. The authorship structure of "ecosystem services" as a transdisciplinary field of scholarship. Ecosystem Services 1, 16-25.

Daily, G.C., Polasky, S., Goldstein, J. Kareiva, P.M., Mooney, H.A., Pejchar, L., Ricketts, T.H. Salzman, J., Shallenberger, R. 2009. Ecosystem services in decision making: time to deliver. Frontiers in Ecology and the Environment 7, 21-28.

de Groot, R.S., Wilson, M.A., Boumans, R.M.J. 2002. A typology for the classification, description and valuation of ecosystem functions, goods and services. Ecological Economics 41, 393-408. 
1 de Groot, R.S., Alkemade, R., Braat, L., Hein, L., Willemen, L. 2010. Challenges in integrating

2 the concept of ecosystem services and values in landscape planning, management and

3 decision making. Ecological Complexity 7, 260-272.

4 Define Research \& Insight 2007. Public understanding of the concepts and language around

5 ecosystem services and the natural environment [online] Available from:

6 http://randd.defra.gov.uk/Default.aspx?Menu=Menu\&Module=More\&Location=None\&Co

7 mpleted=0\&Project|D=15310\#RelatedDocuments Central Office for Information and

8 Department for Environment, Food and Rural Affairs, London, United Kingdom.

9 Ehrlich, P.R., Mooney, H.A. 1983. Extinction, substitution and ecosystem services. BioScience $33,248-254$.

11 Fish, R.D. 2011. Environmental decision making and an ecosystems approach: some 12 challenges from the perspective of social science. Progress in Physical Geography 35, 67113680.

14 Fisher, B., Turner, R.K., Morling, P. 2009. Defining and classifying ecosystem services for 15 decision making. Ecological Economics 68, 643-653.

Foucault, M. 1990/1976. The Will to Knowledge: The History of Sexuality. Volume 1 (R.

17 Hurley, Trans). Penguin, London, United Kingdom.

Friedman, A., \& Thellefsen, M. 2011. Concept theory and semiotics in knowledge organization. Journal of Documentation 67, 644-674. 
1 Frykman, A. 2012. Ecosystem services messaging [online] Available from:

2 http://www.carangeland.org/images/Ecosystem Services Messaging Needs Assessment

$3 \quad$ 072512.pdf Resource Media, California, USA.

4 Gabbert, B., Johnson, D.W., Johnson, R.T. 1986. Cooperative learning, group-to-individual

5 transfer, process gain and the acquisition of cognitive reasoning strategies. Journal of

6 Psychology 120, 265-278.

7 Gómez-Baggethun, E., De Groot, R., Lomas, P. L., Montes, C. 2010. The history of ecosystem

8 services in economic theory and practice: from early notions to markets and payment

9 schemes. Ecological Economics 69, 1209-1218.

10 Harrington, R., Anton, C., Dawson, T. P., de Bello, F., Feld, C. K., Haslett, J. R., Kluvánkova-

11 Oravská, T. Kontogianni, A., Lavorel, S., Luck, G.W., Rounsevell, M.D.A., Samways, M.J.,

12 Settele, J., Skourtos, M., Spangenberg, J.H., Vandewalle, M., Zobel, M., Harrison, P.A. 2010.

13 Ecosystem services and biodiversity conservation: concepts and a glossary. Biodiversity and

14 Conservation 19, 2773-2790.

15 Hein, L., van Koppen, K., de Groot, R.S., van lerland, E.C. 2006. Spatial scales, stakeholders

16 and the valuation of ecosystem services. Ecological Economics 57, 209-228.

17 Janis, I. 1972. Victims of Groupthink: A psychological study of foreign-policy decisions and

18 fiascos. Boston: Houghton Mifflin

19 Lamarque, P., Quétier, F., Lavorel, S. 2011. The diversity of the ecosystem services concept and its implications for their assessment and management. Comptes Rendus Biologies, 334,

$21 \quad 441-449$. 
Lazo, J., Kinnell, J., Fisher, A. 2000. Expert and layperson perceptions of ecosystem risk. Risk Analysis 20, 179-194.

Luck, G. W., Chan, K.M.A., Eser, U., Gómez-Baggethun, E., Matzdorf, B., Norton, B., Potschin, M. 2012. Ethical considerations in on-ground applications of the ecosystem services concept. BioScience 62, 1020-1029.

Mace, G.M., Bateman, I., Albon, S., Balmford, A., Brown, C., Church A., Haines-Young, R., Pretty, J.N., Turner, K., Vira, B., Winn, J. 2011. Conceptual Framework and Methodology. In: The UK National Ecosystem Assessment Technical Report. [online] Available from: http://uknea.unep-wcmc.org/Resources/tabid/82/Default.aspx UNEP-WCMC, Cambridge, UK.

Maynard, S., James, D., Davidson, A. 2010. The development of an ecosystem services framework for South East Queensland. Environmental Management 45, 881-895.

McClean, S. 2003. Doctoring the spirit: Exploring the use and meaning of mimicry and parody at a healing centre in the North of England. Health 7, 483-500.

McKenzie, E., Posner, S., Tillmann, P., Bernhardt, J. R., Howard, K., Rosenthal, A. 2014. Understanding the use of ecosystem service knowledge in decision making: lessons from international experiences of spatial planning. Environment and Planning C: Government and Policy 32, 320-340.

Metz, D., Weigel, L. 2010. Key Findings from Recent National Opinion Research on “Ecosystem Services" [online] Available from: 
1 http://www.conservationgateway.org/Files/Pages/key-findings-recent-natio.aspx

The

2 Nature Conservancy, Montana, USA.

3

4 for Assessment [online] Available from: http://www.unep.org/maweb/en/Framework.aspx

5 Island Press, Washington D.C., USA.

7 Available from: http://www.unep.org/maweb/en/Condition.aspx Island Press, Washington

8 D.C., USA.

10 Crop Science 50, S1-S9.

11 Nahlik, A.M., Kentula, M.E., Fennessy, M.S., Landers, D.H. 2012. Where is the consensus? A 12 proposed foundation for moving ecosystem service concepts into practice. Ecological 13 Economics 77, 27-35.

14 Odum, E.P. 1959. Fundamentals of ecology, 2nd ed, 546 pp. Philadelphia: W.B. Saunders 15 Company.

Peterson, M. J., Hall, D. M., Feldpausch-Parker, A.M., Peterson, T. R. 2010. Obscuring 17 ecosystem function with application of the ecosystem services concept. Conservation Biology 24, 113-119.

19 Prior, L. 2003. Belief, knowledge and expertise: the emergence of the lay expert in medical sociology. Sociology of Health \& IIIness 25, 41-57. 
1 Schröter, M., Zanden, E. H., Oudenhoven, A. P., Remme, R. P., Serna-Chavez, H. M., de

2 Groot, R. S., Opdam, P. In Press. Ecosystem services as a contested concept: a synthesis of

3 critique and counter-arguments. Conservation Letters.

4 Shaw, A. 1999. "What have 'they' done to our food?": Public concerns about food in the UK.

5 Sociological Research Online 4(3).

6 Shaw, M. E. 1932. A comparison of individuals and small groups in the rational solution of

7 complex problems. American Journal of Psychology 44, 491-504.

8 Star, S.L. 2010. This is not a boundary object: reflections on the origin of a concept. Science,

9 Technology and Human Values, 35, 601-617.

10 Star, S. L., Griesemer, J. R. 1989. Institutional ecology, translations' and boundary objects:

11 Amateurs and professionals in Berkeley's Museum of Vertebrate Zoology, 1907-39. Social

12 Studies of Science 19, 387-420.

13 Triplett, N. 1898. The dynamogenic factors in peacemaking and competition. American 14 Journal of Psychology 9, 507-533.

15 Vihervaara, P, Rönkä, M., Walls, M. (2010) Trends in ecosystem service research: early steps 16 and current drivers. Ambio 39, 314-324.

17 Wallace, K.J. 2007. Classification of ecosystem services: problems and solutions. Biological 18 Conservation 139, 235-246. 
1 Wild, K., Church, A., McCarthy, D., Burgess, J. (2013) Quantifying lexical usage: vocabulary

2 pertaining to ecosystems and the environment. Corpora 8, 53-79.

3 Wild, K., McCarthy, D. 2010. A corpus linguistics analysis of ecosystems vocabulary in the

4 public sphere (CLAEVIPS) [online] Available from: http://uknea.unep-

5 wcmc.org/LinkClick.aspx?fileticket=xVtddAx5SbM\%3d\&tabid=82 Lexical Computing Ltd.

6 Commissioned by the United Kingdom National Ecosystem Assessment, UNEP-WCMC,

7 Cambridge, U.K. 